\title{
\begin{tabular}{l|l} 
Mibraries & DSpace@MIT
\end{tabular}
}

\author{
MIT Open Access Articles
}

\section{Integrated Planning for Design and Production in Two-Stage Recycling Operations}

The MIT Faculty has made this article openly available. Please share how this access benefits you. Your story matters.

Citation: Chang, Jiyoun C. et al. "Integrated planning for design and production in two-stage recycling operations." European Journal of Operational Research, 273, 2 (March 2019): 535-547.

As Published: http://dx.doi.org/10.1016/j.ejor.2018.08.022

Publisher: Elsevier BV

Persistent URL: https://hdl.handle.net/1721.1/123987

Version: Author's final manuscript: final author's manuscript post peer review, without publisher's formatting or copy editing

Terms of use: Creative Commons Attribution-NonCommercial-NoDerivs License 


\section{Integrated Planning for Design and Production in Two-Stage Recycling Operations}

Jiyoun C. Chang (corresponding author)

Department of Materials Science and Engineering

Massachusetts Institute of Technology

77 Massachusetts Avenue 8-403

Cambridge, MA 02139

United States

Email: jiyoun@mit.edu, c.jiyoun@gmail.com

Stephen C. Graves

Sloan School of Management

Massachusetts Institute of Technology

77 Massachusetts Avenue E62-579

Cambridge, MA 02139

United States

Email: sgraves@mit.edu

Randolph E. Kirchain

Materials Processing Center

Massachusetts Institute of Technology

77 Massachusetts Avenue E19-695C

Cambridge, MA 02139

United States

Email: kirchain@mit.edu

Elsa A. Olivetti

Department of Materials Science and Engineering

Massachusetts Institute of Technology

77 Massachusetts Avenue 8-403

Cambridge, MA 02139

United States

Email: elsao@mit.edu 


\title{
Integrated Planning for Design and Production in Two-Stage Recycling Operations
}

\author{
Jiyoun C. Chang, Stephen C. Graves, Randolph E. Kirchain, Elsa A. Olivetti
}

\begin{abstract}
Recycling is a key strategy to reduce the environmental impact associated with industrial resource use. Recent improvements in materials recovery technologies offer the possibility for recouping additional value from recycling. However, incorporation of secondary raw materials into production may be constrained by operational complexity in two-stage blending processes. In this paper, we derive an analytical solution to demonstrate the importance of integrated planning (IP) approaches for two-stage blending operations in recycling. Our results suggest that the quality of materials obtained from the first stage strongly influences performance in the second stage. Current disjointed planning (DP) approaches in the recycling industry, where individual stages are independently planned without decision-making about intermediate blend design, overlook this interaction and, therefore, make conservative use of lower quality materials. We develop an IP model using a formulation of the pooling problem and apply it to an industrial-scale aluminum recycling facility located in Europe. The results suggest that the IP model can reduce material costs by more than $5 \%$, for the case examined, and can enable increased use of undervalued raw materials. This study also investigates the impact of variations in operational conditions on the benefits of IP.
\end{abstract}

Keywords: production, material recycling, integrated planning, two-stage blending process (pooling problem), design of intermediate products 


\section{Introduction}

Increasing use of secondary materials within material manufacture may offer both environmental and economic benefits to a producer based on reduced energy use and raw material costs (Ayres, Ferrer, \& Van Leynseele, 1997; Bloemhof-Ruwaard, van Beek, Hordijk, \& Van Wassenhove, 1995; Guide, Jayaraman, Srivastava, \& Benton, 2000; Raz \& Souza, 2018; Thierry, Salomon, Van Nunen, \& Van Wassenhove, 1995). These benefits can be largest if low-value scrap materials can be used to produce high-end material products. However, low-value scrap materials must be separately processed prior to blending with primary material in order to remove unwanted constituents and avoid cross contamination. Thus, value-added production in material recycling commonly leads to two-stage blending operations. As use of these lower quality materials has increased (based on a variety of legislative (European Council, 2011) and market-based factors (Vercammen, Chalabyan, Ramsbottom, Ma, \& Tsai, 2017)), material recycling industries have developed specialized technologies to effectively process them. Electric arc furnaces in steel recycling, deinking processes in paper recycling, reverberatory or rotary furnaces in copper recycling, and rotary furnaces or vortex technology, in aluminum recycling, are examples of recycling technologies targeting low-value raw materials, which rely on two-stage processing. This study develops decision-support models for such recycling operations that require two-stage processing, with a focus on the case of aluminum.

Although two-stage recycling operations exist across the above-mentioned material industries, the case of aluminum is of particular interest. The impact of recycling aluminum is much larger than for any other high-volume material in terms of energy benefits per unit ton (other materials, such as precious metals, exceed the energy benefit but production volumes are smaller). The energy required to produce secondary aluminum is only 5\% of the energy required to produce primary aluminum (Green, 2007; Schlesinger, 2013). This energy benefit has led aluminum producers to produce more metal from scrap, resulting in 40\% increases in the volume of recovered aluminum scrap between 2010 and 2016 (IAI, 2017). Improvement of recycling technologies partially accounts for the recent growth of aluminum recycling. In addition, compared to other material industries, there are a wider variety of high-end aluminum products that can be potentially made from low-value scrap, thanks to recent improvements in processing technologies. Thus, the potential benefits of improving two-stage recycling operations are substantial for aluminum producers.

One important planning consideration in two-stage processing is the quality of the materials produced in the first stage. Depending on their compositional specifications, these so-called intermediate blends can be used in the downstream production of either high-end or low-end products. While the former is more profitable, only limited amounts of intermediate blends are currently used in the 
production of high-end aluminum products due to the compositional mismatch between intermediate blends and high-end products. Despite the importance of intermediate blend quality, in current aluminum recycling practice, designs are invariant to downstream demand. The primary reason is that the existing planning models are incapable of determining the design of intermediate blends. There may be a few other reasons for this relatively disjointed planning practice. Historically, before the recent improvements in processing technologies, intermediate blends made of low-quality scrap were used only in the production of low-end products for which the composition of intermediate blends is not problematic. Also, the first stage of a two-stage recycling operation (i.e., the production of intermediate blends) is often performed by outside contractors at a fixed cost per weight of materials processed, making the coordination relatively difficult. Additionally, if aluminum producers fail to use intermediate blends downstream based on problematic compositional specifications, they can still sell cast forms of these intermediate blends as sows (i.e., large cast ingots). The market value of sows, which do not meet the compositional requirement of a specific alloy product, is determined not by their specifications, but by their metal content. These conditions may have delayed the realization of the importance of the design of intermediate blends in the aluminum industry.

Therefore, to maximize the benefit of recycling by using low-value scrap in high-end products, we have developed and applied an integrated framework to support two-stage recycling operations. This study investigates two research questions: 1 ) How does the design of intermediate blends influence the performance in two-stage recycling operations? and 2) Can an integrated planning model with explicit consideration of designs of intermediate blends improve the current underutilization of scrap in the material recycling industry? Aspects of this model development have supported operational decisions in three aluminum recycling facilities located in Europe (that use two-stage blending processes). Beyond these applications, the goal of this study is to understand the importance of designing intermediate blends and the benefits of extending the scope of planning decisions to cover two-stage recycling operations more broadly. The formulation and insights from this study can be applied to other material recycling processes. A key contribution from our study is to demonstrate how operations research can increase the profitable use of secondary materials.

This article is organized as follows. The next section provides a brief review of relevant literature. Section 3 describes the model development of integrated planning for two-stage recycling operations and, for comparison, a model for disjointed planning based on current practice in the industry. In Section 4, we use a simplified analysis of the two-stage recycling operation to illustrate the importance of intermediate product designs. Section 4 answers the first research question by using analytically driven mathematical relationships. In Section 5, we apply the two models introduced in Section 3 to a real-world aluminum 
recycling case and demonstrate the benefits from the integrated planning model in two-stage recycling operations. This section ends with a sensitivity analysis on the impacts due to some operational parameters. Finally, we draw conclusions and provide future research directions.

\section{Literature Review}

In the field of operations research, material recycling has been discussed as part of planning for remanufacturing operations (Galbreth \& Blackburn, 2006; Jayaraman, 2006). Decisions regarding material recycling in remanufacturing are generally limited to determining what fraction of a set of unrecoverable components should be recycled (Galbreth \& Blackburn, 2006; Johnson \& Wang, 1995). Although both recycling and remanufacturing operations aim at returning the recoverable portion of objects from the end-of-life into an earlier stage of the life cycle, planning for recycling requires different operational decisions (Raz \& Souza, 2018). Because products are made of a fixed set of discrete components, decision variables for remanufacturing are generally limited to how to allocate components across applications (Galbreth \& Blackburn, 2006). Materials, in contrast, do not have a fixed recipe. As such, decision variables involve allocation of materials across applications and the intensity of allocation within applications. This difference necessitates developing different decision-support tools for material recycling operations.

Operational decisions determine the type and volume of materials that flow through a set of transformative processes. Since production outputs need to satisfy required specifications in order to be sold in the market, a production planning tool for material recycling must be able to properly model the influence that material flows have on quality (Fröhling, Schwaderer, Bartusch, \& Rentz, 2010). Production in material recycling operations can be viewed as a blending problem among several raw materials, both secondary (i.e., recycled) and primary (i.e., virgin). The blending problem is an essential task in many industries and its applications range from food (Steuer, 1984) and chemical fertilizer (Ashayeri, van Eijs, \& Nederstigt, 1994) to steel (Fabian, 1958) and fuel production (Symonds, 1956). The most simplified version of the blending problem is a one-stage linear blending model. This type of model in a material recycling operation has been further extended through the consideration of compositional uncertainty of raw materials using a chance-constraint formulation (Gaustad, Li, \& Kirchain, 2007) and fuzzy logic constraints (Rong \& Lahdelma, 2008), and the consideration of logistics costs (Fröhling et al., 2010). However, these studies investigate the cases of one-stage blending operations. Thus, neither intermediate blends nor their design has been discussed in these contributions. Although Kirchain and Cosquer studied how the design of final alloy products affect scrap consumption of aluminum recyclers (Kirchain \& Cosquer, 2007), this study (again, as an one-stage blending model) does 
not answer how the designs of intermediate blends influence the blending decisions in downstream production or the overall performance of two-stage recycling operations.

Determining the optimal design of intermediate blends in two-stage recycling operations requires an integrated approach, coordinating decisions across two stages as well as considering different levels of decisions. The concept of coordinating decisions across different stages, which is common in supply chain management, has not been widely applied to recycling operations. There are only a few studies of recycling operations, where detailed modeling is necessary to address the interdependences between the operational decisions and material quality. Spengler et al. developed an integrated optimization model for planning dismantling and recycling of buildings (Spengler, Püchert, Penkuhn, \& Rentz, 1997). Van Schaik et al. used an optimization model for recycling end-of-life vehicles that involves both mechanical recycling and metallurgical operations due to the interconnection between resources in the system (van Schaik, Reuter, Boin, \& Dalmijn, 2002). In addition, design-related decisions are generally separately planned from opearational decisions. A review by Govindan et al. also suggests that studies integrating operational decision variables (e.g., production planning) with strategic or tatical decision variables (e.g., designing) still remain scarce in the field of reverse logistics and closed-loop supply chains (Govindan, Soleimani, \& Kannan, 2015). Salema et al. developed a model for the simultaneous design and planning of supply chains with reverse flows (Salema, Barbosa-Povoa, \& Novais, 2010). Fröhling et al. proposed an integrated planning framework for zinc recycling, considering both strategic and operational decisions. Their proposed model determines network design to source industrial byproduct and production plans for blending operations in zinc refining plants (Fröhling et al., 2010). However, we are not aware of any research that develops an optimization model for two-stage blending recycling operations with the consideration of the design of intermediate products or demonstrates its implementation for a real-world case.

In operations research, the blending problem with more than one stage is called the pooling problem. The pooling problem was first introduced in the fuel refinery industry (DeWitt, Lasdon, Waren, Brenner, \& Melhem, 1989; Haverly, 1978). Since the pooling problem is nonlinear and nonconvex due to bilinear terms, most studies about the pooling problem focus on finding improved solutions (Adhya, Tawarmalani, \& Sahinidis, 1999; Audet, Brimberg, Hansen, Digabel, \& Mladenović, 2004; Li, Armagan, Tomasgard, \& Barton, 2011; Meyer \& Floudas, 2006). Thanks to these efforts, the solution time for the pooling problem has been greatly reduced over the past several decades. However, the pooling problem has not yet been applied in the field of material recycling.

This paper is the first to use the pooling problem as an integrated planning approach for an applied material recycling operation. The production system in this study differs from existing 
applications of the pooling problem in two key aspects. First, the intermediate blends are perishable. The storage of the intermediate blends for later use requires transforming them into a stable form (e.g., solid) to prevent quality deterioration. Later, transforming them back to a blendable form (e.g., melting) requires additional energy use by material producers. Thus, substantial energy savings occur when the downstream stage can immediately use intermediate blends. Second, both final products and feedstocks are highly diverse in product quality, and the product specifications are compositionally asymmetric. For aluminum metal products, specifications are defined in terms of the relative fractions of alloying elements in the base metal (aluminum); these fractions are small. Depending on the relative fraction of these alloying elements, final alloy metal products exhibit unique mechanical, thermal or electrical properties. Hundreds (if not thousands) of distinct alloys can be produced based on the combinations of different alloying elements. Thus, the product portfolio for metal producers is much more diverse than for the fuel refinery industry.

To the best of our knowledge, no previous research has studied the influence of intermediate blend design on the performance of two-stage recycling operations or developed decision-support tools for such operations despite the potential benefits for the material industry. Our study will fill these gaps by presenting how an integrated approach can improve the current recycling practices for a two-stage aluminum blending operation.

\section{Model development for two-stage blending operations in aluminum recycling}

Rotary furnaces or vortex technologies are specialized to process low-quality raw materials, such as byproducts from aluminum production (dross) or used beverage cans. Outputs from these reprocessing furnaces are aluminum alloy products themselves that can be sold in the market, based on their metal contents. However, they can be further upgraded into higher-value alloy products through additional blending with primary metal and alloying elements to satisfy tighter specifications in a second-stage process. This value-added aluminum recycling leads to a two-stage blending process as described in Figure 1: the reprocessing stage and the remelting stage. In the reprocessing stage (i.e., the first stage), aluminum dross and scrap materials are blended in a rotary furnace or vortex technology generating intermediate blends, called recycled products (RPs). In the remelting stage (i.e., the second stage), RPs are blended with primary aluminum and alloying elements to create final alloy products. 


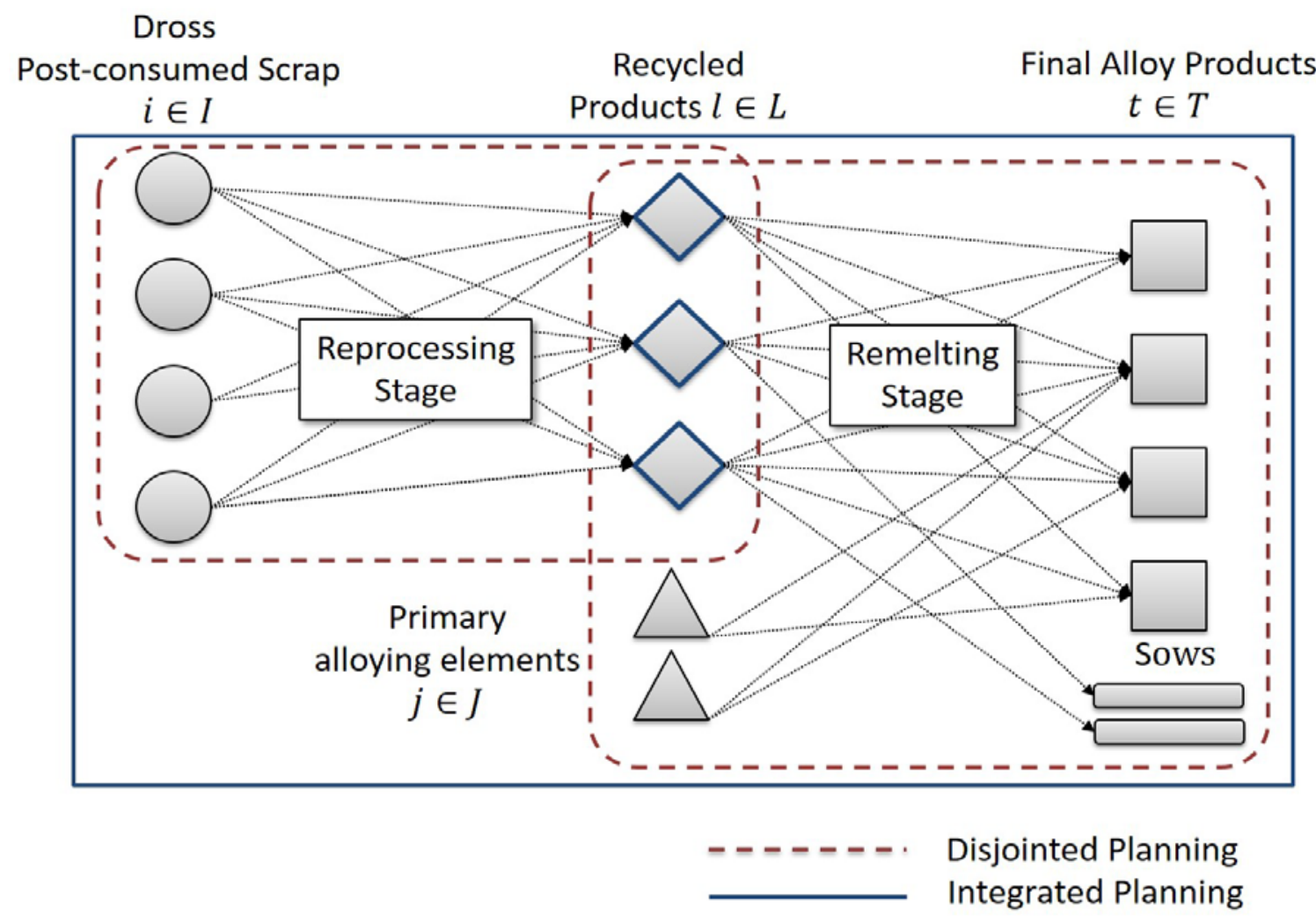

Figure 1. Schematic description of two-stage aluminum recycling operation and decision scope of two different planning approaches, disjointed planning (red dashed line) and integrated planning (blue solid line)

In this two-stage recycling process, there are two performance metrics: 1) the total cost of raw materials used to produce final products and 2) how much of the RPs used in final alloy production as liquid metal (as opposed to sows). We choose these metrics for two reasons. First, the cost of purchasing raw material dominates other cost elements (74\% of the total cost in 2014) in the aluminum industry (Goddard, 2014). Producing final alloy products at the minimum cost of raw materials is the primary objective in this industry. Second, since aluminum liquid metal readily oxidizes when exposed to the atmosphere, RPs must be cast as sows to avoid metal loss if they are not immediately used. Using sows in subsequent production requires significant energy to remelt them. Therefore, to maximize the economic benefit of reprocessing technologies, the RPs should be immediately input as liquid metal in downstream remelting furnaces (Peterson \& Blagg, 2013). In other words, the more RPs that are used in liquid form, the more the final alloy products consist of low-value raw materials, which have been processed with less energy; This benefit is possible even when the reprocessing stage is performed by an outside contractor that is located close by (Schlesinger, 2013). The amount of RPs used as liquid metal is the second performance metric to quantify this benefit. 
We compare two planning approaches for determining daily batch plans in a two-stage recycling facility as illustrated in Figure 1: disjointed planning (DP) and integrated planning (IP). In DP, the reprocessing stage and the remelting stage are independently planned using one-stage blending models without an explicit, coordinated design of the RPs. In DP, planning for the reprocessing stage always precedes planning for the remelting stage. Meanwhile, in IP, blending decisions for both stages as well as decisions for the specification of RPs are made simultaneously by using a two-stage blending formulation (i.e., the pooling problem formulation). The rest of this section formulates these IP and DP models. The descriptions for parameters and decision variables used in the two models are summarized in Table 1.

Table 1. Nomenclature used in integrated planning and disjointed planning models.

\begin{tabular}{|c|c|c|}
\hline Type & Symbol & Description \\
\hline \multirow{5}{*}{$\begin{array}{l}\text { Set and } \\
\text { Indices }\end{array}$} & $i \in I$ & The set of dross and scrap materials (for the first stage of blending) \\
\hline & $j \in J$ & The set of primary and alloying materials (for the second stage of blending) \\
\hline & $l \in L$ & The set of batches for recycled products \\
\hline & $t \in T$ & The set of batches for finished alloys \\
\hline & $k \in K$ & The set of compositional elements \\
\hline \multirow[t]{14}{*}{ Parameters } & $A_{i}$ & Maximum available weight of dross and scrap material $i$ (IP only) \\
\hline & $A_{j}$ & Maximum available weight of primary and alloying material $j$ \\
\hline & $c_{i}$ & Unit cost of dross and scrap material $i$ \\
\hline & $c_{j}$ & Unit cost of primary and alloying material $j$ \\
\hline & $e_{i, k}$ & Weight fraction of an element $k$ in dross and scrap material $i$ \\
\hline & $e_{j, k}$ & Weight fraction of an element $k$ in primary or alloying material $j$ \\
\hline & $D_{t}$ & Weight of demand for final product of batch $t$ \\
\hline & $V_{\max }$ & Upper limit of rotary furnace capacity for each batch in weight (IP only) \\
\hline & $V_{\min }$ & Lower limit of rotary furnace capacity for each batch in weight (IP only) \\
\hline & $e_{t, k}^{U}$ & Upper limit of weight fraction of an element $k$ in final product of batch $t$ \\
\hline & $e_{t, k}^{L}$ & Lower limit of weight fraction of an element $k$ in final product of batch $t$ \\
\hline & $c_{l}$ & Unit material cost of recycled product of batch $l$ (DP only) \\
\hline & $e_{l, k}$ & Weight fraction of an element $k$ in recycled product of batch $l$ (DP only) \\
\hline & $g_{i, l}$ & Weight of dross and scrap material $i$ used in recycled product of batch $l$ (DP only) \\
\hline \multirow{7}{*}{$\begin{array}{l}\text { Decision } \\
\text { Variables } \\
\text { in IP }\end{array}$} & $f_{i, l}$ & Weight of dross and scrap material $i$ used in recycled product of batch $l$ \\
\hline & $f_{j, t}$ & Weight of primary or alloying material $j$ used in batch for product $t$ \\
\hline & $\varepsilon_{l, k}$ & $\begin{array}{l}\text { (Quality formulation) Weight fraction of an element } k \text { in recycled product of } \\
\text { batch } l\end{array}$ \\
\hline & $f_{l, t}$ & $\begin{array}{l}\text { (Quality formulation) Weight of recycled product produced in batch } l \text { and used in } \\
\text { final product of batch } t\end{array}$ \\
\hline & $R_{l}$ & $\begin{array}{l}\text { (Quality formulation) Weight of recycled product produced in batch } l \text { but not used } \\
\text { in final alloy production }\end{array}$ \\
\hline & $E_{l, k}$ & (Proportional formulation) Weight of an element $k$ in recycled product of batch $l$ \\
\hline & $q_{l, t}$ & $\begin{array}{l}\text { (Proportional formulation) The proportion of recycled product of batch } l \text { used in } \\
\text { final product of batch } t\end{array}$ \\
\hline
\end{tabular}


$r_{l} \quad$ (Proportional formulation) The proportion of recycled product produced in batch $l$ but not used in final alloy production

\begin{tabular}{lll}
\hline Decision & $f_{j, t}$ & Weight of primary or alloying material $j$ used in final product of batch $t$ \\
Variables & $f_{l, t}$ & Weight of recycled product produced in batch $l$ and used in final product of batch \\
in DP & & $t$ \\
& $R_{l}$ & $\begin{array}{l}\text { Weight of recycled product produced in batch } l \text { but not used in final alloy } \\
\text { production }\end{array}$ \\
\hline
\end{tabular}

\subsection{Mathematical formulations for integrated planning}

This section presents two formulations for IP: quality formulation and proportional formulation.

While both formulations are equivalent, they differ based on how we model the flows of alloying elements from RPs to final products. As the number of quality attributes increases, the number of bilinear constraints in the quality formulation grows faster than in the proportional formulation (Quesada \& Grossmann, 1995). The quality formulation provides more direct information about the relationship between the design of RPs and the final product specifications, but the proportional formulation is more efficient for large-scale problems. Therefore, we use the quality formulation for the hypothetical example in Section 4 and the proportional formulation for solving the case example in Section 5.

\section{(Quality formulation)}

Objective function

$$
\min \sum_{i} c_{i} \sum_{l} f_{i, l}+\sum_{j} c_{j} \sum_{t} f_{j, t}
$$

Subject to

$$
\begin{gathered}
\sum_{l} f_{i, l} \leq A_{i} \quad \forall i \\
\sum_{t} f_{j, t} \leq A_{j} \quad \forall j \\
\sum_{i} f_{i, l} \leq V_{\text {max }} \quad \forall l \\
\sum_{i} f_{i, l} \geq V_{\min } \quad \forall l \quad \\
\sum_{i} e_{i, k} f_{i, l}-\varepsilon_{l, k} \sum_{i} f_{i, l}=0 \quad \forall l, k \\
\sum_{t} f_{l, t}+R_{l}=\sum_{i} f_{i, l} \quad \forall l \\
\sum_{l} f_{l, t}+\sum_{j} f_{j, t}=D_{t} \quad \forall t \quad \\
\sum_{l} \varepsilon_{l, k} f_{l, t}+\sum_{j} e_{j, k} f_{j, t} \leq e_{t, k}^{U} D_{t} \quad \forall t, k \\
\sum_{l} \varepsilon_{l, k} f_{l, t}+\sum_{j} e_{j, k} f_{j, t} \geq e_{t, k}^{L} D_{t} \quad \forall t, k \\
f_{i, l}, f_{j, t}, f_{l, t}, R_{l}, \varepsilon_{l, k} \geq 0 \quad \forall i, j, k, l, t \\
\varepsilon_{l, k} \leq 1 \quad \forall l, k
\end{gathered}
$$

The objective function (1) minimizes the costs of all raw materials used in both the reprocessing and remelting stages. We note that no term is associated with flows of RPs $\left(f_{l, t}\right)$ since using RPs requires no purchase of raw materials. Constraints (2) and (3) ensure that the total amount of each raw material 
used in production is within the upper limit of its availability. Constraints (4) and (5) describe the upper and lower bounds of the size of each batch in the rotary furnace. Constraint (6) describes the mass balance for each compositional element, meaning that the sum of each compositional element of dross and other scrap materials used in an RP is equal to the same compositional element of in that RP. Eq. (7) describes mass balances of RPs. Each RP produced is either used in the final products or cast as a sow. Eq. (8) expresses the demand requirement for each batch of final products. Constraints (9) and (10) ensure that the final blends satisfy the maximum and minimum quality specifications of the final products. Constraints (11) represents the non-negativity of decision variables. Constraints (12) represents the upper bound of the quality variables of RPs.

To model the flows of compositional elements from RPs (pools) to products (terminals), the quality formulation uses the flow between RP $l$ and product $t\left(f_{l, t}\right)$, and the relative quality within the flow $\left(\varepsilon_{l, k}\right)$, while the proportional formulation uses the total weight of the compositional elements within an RP $l\left(E_{l, k}\right)$ and the proportion of flow leaving an RP node $\left(q_{l, t}\right.$ and $\left.r_{l}\right)$ (Ben-Tal, Eiger, \& Gershovitz, 1994). The proportional formulation replaces Constraints (6)-(10) with (13)-(17) and Constraint (11) with (18), respectively. Constraints (19) provide the upper bounds of the proportional variables. Both formulations have bilinear terms in the compositional requirement constraints of final products as Eq. (9)(10) and Eq. (16)-(17). In addition, the quality formulation has the bilinear terms in the compositional mass balance constraints at the pool nodes (Eq. (6)) whereas the proportional formulation has in demand requirement constraints at the terminal node (Eq. (15)). Thus, the proportional formulation has fewer nonlinear constraints than the quality formulation with increasing number of alloying elements.

\section{(Proportional formulation)}

$$
\begin{gathered}
\sum_{i} e_{i, k} f_{i, l}=E_{l, k} \quad \forall l, k \\
\sum_{t} q_{l, t}+r_{l}=1 \quad \forall l \quad \forall t \\
\sum_{l} q_{l, t}\left(\sum_{i} f_{i, l}\right)+\sum_{j} f_{j, t}=D_{t} \quad \forall t \quad \forall t, k \\
\sum_{l} E_{l, k} q_{l, t}+\sum_{j} e_{j, k} f_{j, t} \leq e_{t, k}^{U} D_{t} \quad \forall t, k \\
\sum_{l} E_{l, k} q_{l, t}+\sum_{j} e_{j, k} f_{j, t} \geq e_{t, k}^{L} D_{t} \quad \forall i, j, k, l, t \\
f_{i, l}, f_{j, t}, q_{l, t}, r_{l}, E_{l, k} \geq 0 \quad \forall i, t \\
q_{l, t}, r_{l} \leq 1 \quad \forall l
\end{gathered}
$$

\subsection{Mathematical formulation for disjointed planning}

Current planning practices for the reprocessing stage fall into two categories: 1) predetermined recipe and 2) predetermined design. In the case of the predetermined recipe, plans are made for which materials to process in the reprocessing stage. However, the RPs produced from predetermined recipes are 
not intended to be used in a specific final product. Often, raw materials are reprocessed as soon as they arrive at a plant rather than following a specific planned recipe. Consequently, the compositions of RPs vary from batch to batch. In the case of the predetermined design, there is one predetermined design for RPs. Each batch may use different raw materials determined by a one-stage blending model but resulting compositions of RPs do not vary. For the DP model in this study, we use the predetermined recipe approach.

In either case, however, planning for the remelting stage comes after the production of RPs in the current practices. The compositions and the volume of RPs are already determined at the time of decisions for the remelting stage. Thus, the DP model can be considered as a special case of the quality formulation of the IP model in which the decision variables relevant to the reprocessing stage $\left(f_{i, l}\right)$ are replaced by parameters $\left(g_{i, l}\right)$ (or decisions already made in the reprocessing stage). The compositions of RPs become

$$
e_{l, k}=\frac{\sum_{i} e_{i, k} g_{i, l}}{\sum_{i} g_{i, l}}
$$

Thus, constraints (9) and (10) are no longer bilinear. The resulting DP model is a simple linear one-stage blending problem for the remelting stage, given the compositions and availability of the RPs as input parameters calculated from a predetermined recipe. The predetermined recipe $\left(g_{i, l}\right)$ used in DP satisfies constraints (2), (4) and (5) in IP formulation. Thus, the DP model is applied for determining plans for the same operational conditions as IP model.

\section{Objective function}

$$
\min \sum_{l} c_{l} \sum_{t} f_{l, t}+\sum_{j} c_{j} \sum_{t} f_{j, t}
$$

\section{Subject to}

$$
\begin{gathered}
\sum_{t} f_{j, t} \leq A_{j} \quad \forall j \\
\sum_{t} f_{l, t}+R_{l}=\sum_{i} g_{i, l} \quad \forall l \\
\sum_{l} f_{l, t}+\sum_{j} f_{j, t}=D_{t} \quad \forall t \\
\sum_{l} e_{l, k} f_{l, t}+\sum_{j} e_{j, k} f_{j, t} \leq e_{t, k}^{U} D_{t} \quad \forall t, k \\
\sum_{l} e_{l, k} f_{l, t}+\sum_{j} e_{j, k} f_{j, t} \geq e_{t, k}^{L} D_{t} \quad \forall t, k \\
f_{j, t}, f_{l, t}, R_{l} \geq 0 \quad \forall j, l, t
\end{gathered}
$$

The objective function (21) minimizes the cost of raw materials used in the final alloy production. We define the unit material cost of a $\mathrm{RP}\left(c_{l}\right)$ as the cost of purchasing raw materials used to produce a RP, which is

$$
c_{l}=\frac{\sum_{i} c_{i} g_{i, l}}{\sum_{i} g_{i, l}}
$$


Therefore, the first term in the objective function represents the cost of raw materials used in the reprocessing stage that actually contribute to the final alloy production. Constraint (22) describes the availability limit for primary aluminum and alloying elements. Constraint (23) says that the RPs produced are either used in final products or cast as sows. Constraint (24) expresses the demand requirement for final alloy products. Constraints (25) and (26) ensure the final blends in the remelting furnace satisfy the upper and lower specification of final products. Constraints (27) require the non-negativity of decision variables.

\section{Analytical understanding of simplified two-stage blending operations}

We develop and analyze a small hypothetical example to understand the analytical relationship between blending decisions of two-stage operations in the context of metallurgical batch planning. Figure 2(a) illustrates a simple two-stage recycling operation with four raw materials (two low-quality scrap materials $(1,2 \in I)$ in the reprocessing stage, primary aluminum $(3 \in J)$ and one alloying element $(4 \in J)$ in the remelting stage; two final products $(A, B \in T)$ and one quality attribute (i.e., tracking one alloying element $(n(K)=1)$, thus, two materials system). There is one intermediate blend ( $p \in L)$ made of Scrap 1 and 2, called the recycled product (RP).

For the purpose of this hypothetical example, we use the quality formulation of IP introduced in Section 3 without considering capacity and availability constraints in Eq. (2)-(5) and assuming all RP produced is used $\left(R_{l}=0\right.$ in Eq. (7)). This example assumes that Scrap 1 is compositionally purer than Scrap $2\left(e_{1}<e_{2}\right)$ and the specification range for Product $\mathrm{A}$ is compositionally purer than for Product $\mathrm{B}$ $\left(e_{A}^{L}<e_{A}^{U}<e_{B}^{L}<e_{B}^{U}\right)$. This hypothetical example is to determine blending decisions for both stages that minimize the total material cost, using four raw materials to produce a unit weight of each final product A and B while satisfying their specifications, and mass and compositional balance at each node. 
(a)

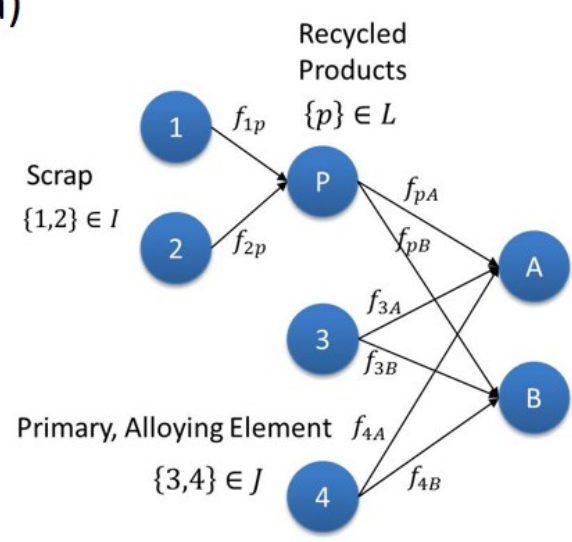

(c)

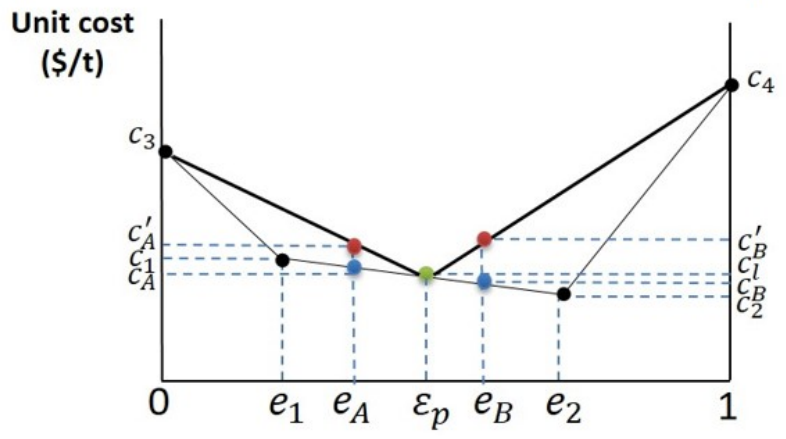

The relative amount of the alloying element (b)

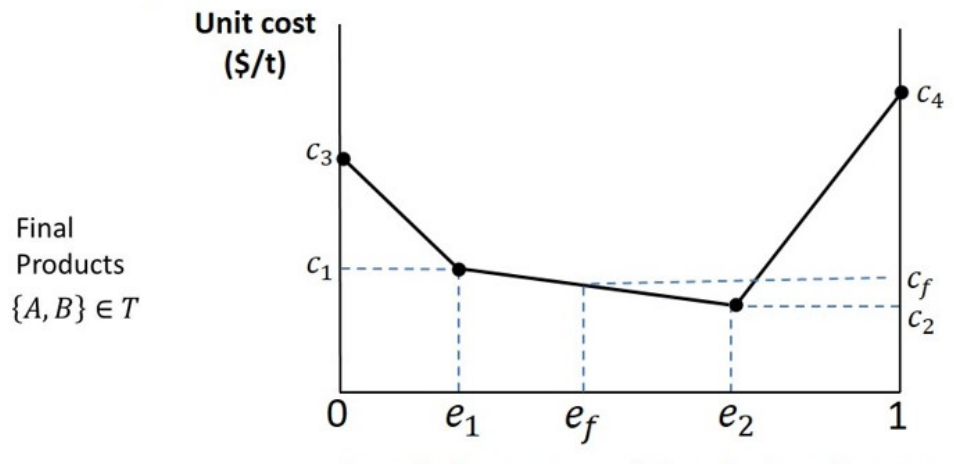

The relative amount of the alloying element

(d)

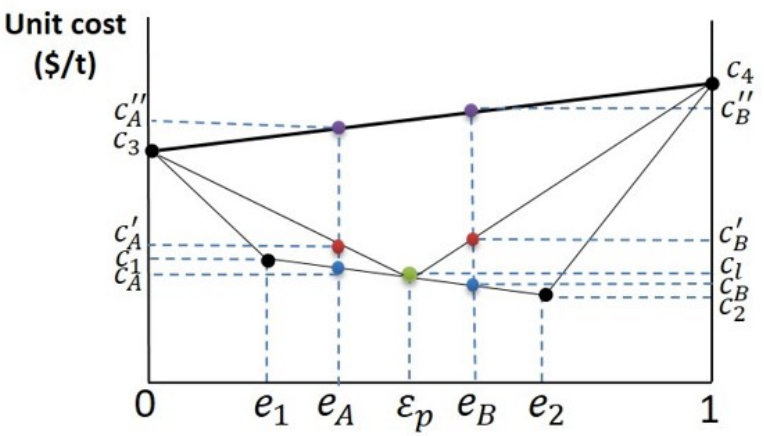

The relative amount of the alloying element

Figure 2. (a) Schematic description of hypothetical case study which consists of four raw materials (two scrap materials, primary aluminum, and alloying element), one RP, and two final products. Composition-cost plots to represent the cost of a final blend (b) when all raw materials can be blended in a single stage, (c) in two-stage blending and (d) in one-stage blending without reprocessing stage.

The graph in Figure 2(b) shows the compositions and costs of the raw materials in Figure 2(a). The $\mathrm{x}$-axis of the graph represents the composition in terms of the relative amount of the alloying element in a raw material. The y-axis represents the cost of raw materials. Primary aluminum is located on the left end $\left(e_{3}=0\right)$, and the alloying element is located on the right end $\left(e_{4}=1\right)$. Scrap materials are located between primary aluminum and the alloying element on the x-axis and below them on the y-axis because most scrap materials are cheaper than pure raw materials. If all raw materials can be blended in one stage without reprocessing, which is technically impossible due to separate blending requirement for lowquality raw materials, the minimum cost of making a final blend will be determined by the convex hull of these points as line segments in Figure 2(b). In other words, any blend of raw materials whose connecting line does not define the convex hull is not part of the solution that minimizes the material cost. For 
example, the minimum cost to make a unit weight of the blend with the composition $e_{f}$ is $c_{f}$. The raw materials to make such a blend are two points connecting the line of the convex hull at $e_{f}$, which are Scrap 1 and 2.

The key difference between one-stage and two-stage recycling operations is that scrap materials must be blended separately prior to blending with primary metal and alloying elements. Given this, the blending ratio of the first-stage raw materials must be the same across all final products made of the same RP. Thus, in this hypothetical example, the blending ratio of Scrap 1 and 2 must be the same in products A and B because we consider only one RP. The only available raw materials in the second stage are primary aluminum, the alloying element, and the RP (the blend of Scrap 1 and 2). This constraint is imposed by the two-stage recycling operation, and changes the shape of the convex hull in the composition-cost graph from Figure 2(b) to Figure 2(c). In particular, we see in Figure 2(c) that the cost function is determined by the two points corresponding to the pure raw materials, and the green point representing the RP. Thus, for an arbitrary composition of the RP $\left(\varepsilon_{p}\right)$, the cost of producing a unit volume of Products $\mathrm{A}$ and $\mathrm{B}$ in a two-stage recycling operation is therefore $c_{A}^{\prime}$ and $c_{B}^{\prime}$ (red points), respectively, instead of $c_{A}$ and $c_{B}$ (blue points), which are technically unachievable due to reprocessing requirement for Scrap 1 and 2. However, the production of final products with the reprocessing stage is still cheaper than the production without the reprocessing stage (see $c_{A}^{\prime \prime}$ and $c_{B}^{\prime \prime}$ (purple points) as shown in Figure 2(d)). Thus, the reprocessing stage enables use of low-quality raw materials, thereby reducing the production cost.

Table 2. Summary of the composition of final products, minimum material costs, and the blending ratios. (The subscript $t$ can be either of final products $A$ or $B$ )

\begin{tabular}{|c|c|c|c|c|c|c|}
\hline \multirow{2}{*}{ Scenarios } & \multirow{2}{*}{$\begin{array}{c}\text { RP composition } \\
\left(\boldsymbol{\varepsilon}_{\boldsymbol{p}}\right)\end{array}$} & $\begin{array}{c}\text { Composition } \\
\text { of final blend }\end{array}$ & $\begin{array}{c}\text { The minimum unit material } \\
\text { cost of } \\
\text { a final product }\end{array}$ & \multicolumn{2}{|c|}{$\begin{array}{c}\text { Optimal blending decisions } \\
\text { in the second stage }\end{array}$} \\
\cline { 5 - 7 } & $\varepsilon_{p}<e_{t}^{L}$ & $e_{f}=e_{t}^{L}$ & $c_{p}\left(\frac{e_{4}-e_{t}^{L}}{e_{4}-\boldsymbol{D}_{p}}\right)+c_{4}\left(\frac{e_{t}^{L}-\varepsilon_{p}}{e_{4}-\varepsilon_{p}}\right)$ & $\frac{e_{4}-\boldsymbol{D}_{t}}{e_{4}-\varepsilon_{p}}$ & 0 & $\frac{\boldsymbol{f}_{4 t} / \boldsymbol{D}_{\boldsymbol{t}}}{e_{t}-\varepsilon_{p}}$ \\
\hline (I) & $e_{t}^{L} \leq \varepsilon_{p} \leq e_{t}^{U}$ & $e_{f}=\varepsilon_{p}$ & $c_{p}$ & 1 & 0 & 0 \\
\hline (II) & $\varepsilon_{p}>e_{t}^{U}$ & $e_{f}=e_{t}^{U}$ & $c_{p}\left(\frac{e_{t}^{U}-e_{3}}{\varepsilon_{p}-e_{3}}\right)+c_{3}\left(\frac{\varepsilon_{p}-e_{t}^{U}}{\varepsilon_{p}-e_{3}}\right)$ & $\frac{e_{t}^{U}-e_{3}}{\varepsilon_{p}-e_{3}}$ & $\frac{\varepsilon_{p}-e_{t}^{U}}{\varepsilon_{p}-e_{3}}$ & 0 \\
\hline
\end{tabular}

The objective of this problem is to find the blending decision that minimizes the total material cost (TMC) with the reprocessing stage, the sum of $c_{A}^{\prime}$ and $c_{B}^{\prime}$. The shape of the convex hull, which defines the minimum material cost of individual final products, depends on the composition $\left(\varepsilon_{p}\right)$ and the cost $\left(c_{p}\right)$ of the RP. Similarly, the minimum material cost of the RP with an arbitrary composition is defined by the convex hull of low-quality raw materials in the reprocessing stage (which is simply the 
linear combination of the cost and composition of Scrap1 and Scrap 2 in this example). The optimal blending decisions of both stages are determined by the lever rule (see SI for more details on the lever rule).

The composition of the RP relative to the specification of a final product determines which segment of the convex hull is the cost function for that particular product. In other words, the cost function of an individual final product in a two-stage blending operation is a piecewise function. In this hypothetical example, there are three scenarios: (I) the composition of the RP is lower than the minimum specification of a final product (out-of-min specification), (II) the composition of the RP is within the specification of a final product, or (III) the composition of the RP is higher than the maximum specification of a final product (out-of-max specification). Each scenario represents a segment or a point of the convex hull and, therefore, has a different set of raw materials as the optimal second-stage blending decision. Consequently, the TMC, the sum of the cost functions of two individual final products, is also a piecewise function, which can be expressed as the combination of two scenarios from Table 2. In this particular example where $e_{A}^{L}<e_{A}^{U}<e_{B}^{L}<e_{B}^{U}$, the expression of TMC becomes (Chang, 2015)

$$
T M C=\left\{\begin{array}{cr}
D_{A}\left(c_{p} \frac{e_{4}-e_{A}^{L}}{e_{4}-\varepsilon_{p}}+c_{4} \frac{e_{A}^{L}-\varepsilon_{p}}{e_{4}-\varepsilon_{p}}\right)+D_{B}\left(c_{p} \frac{e_{4}-e_{B}^{L}}{e_{4}-\varepsilon_{p}}+c_{4} \frac{e_{B}^{L}-\varepsilon_{p}}{e_{4}-\varepsilon_{p}}\right), & \boldsymbol{\varepsilon}_{\boldsymbol{p}}<e_{A}^{L} \\
D_{A} c_{p}+D_{B}\left(c_{p} \frac{e_{4}-e_{B}^{L}}{e_{4}-\varepsilon_{p}}+c_{4} \frac{e_{B}^{L}-\varepsilon_{p}}{e_{4}-\varepsilon_{p}}\right), & e_{A}^{L} \leq \boldsymbol{\varepsilon}_{\boldsymbol{p}} \leq e_{A}^{U} \\
D_{A}\left(c_{p} \frac{e_{A}^{U}-e_{3}}{\varepsilon_{p}-e_{3}}+c_{3} \frac{\varepsilon_{p}-e_{A}^{U}}{\varepsilon_{p}-e_{3}}\right)+D_{B}\left(c_{p} \frac{e_{4}-e_{B}^{L}}{e_{4}-\varepsilon_{p}}+c_{4} \frac{e_{B}^{L}-\varepsilon_{p}}{e_{4}-\varepsilon_{p}}\right), & e_{A}^{U}<\boldsymbol{\varepsilon}_{\boldsymbol{p}}<e_{B}^{L} \\
D_{A}\left(c_{p} \frac{e_{A}^{U}-e_{3}}{\varepsilon_{p}-e_{3}}+c_{3} \frac{\varepsilon_{p}-e_{A}^{U}}{\varepsilon_{p}-e_{3}}\right)+D_{B} c_{p}, & e_{B}^{L} \leq \boldsymbol{\varepsilon}_{\boldsymbol{p}} \leq e_{B}^{U} \\
D_{A}\left(c_{p} \frac{e_{A}^{U}-e_{3}}{\varepsilon_{p}-e_{3}}+c_{3} \frac{\varepsilon_{p}-e_{A}^{U}}{\varepsilon_{p}-e_{3}}\right)+D_{B}\left(c_{p} \frac{e_{B}^{U}-e_{3}}{\varepsilon_{p}-e_{3}}+c_{3} \frac{\varepsilon_{p}-e_{B}^{U}}{\varepsilon_{p}-e_{3}}\right), & \boldsymbol{\varepsilon} \boldsymbol{p}>e_{B}^{U} \\
\text { where } c_{p}=c_{1} \frac{e_{2}-\varepsilon_{p}}{e_{2}-e_{1}}+c_{2} \frac{\varepsilon_{p}-e_{1}}{e_{2}-e_{1}} &
\end{array}\right.
$$

We demonstrate how the TMC changes in two-stage recycling operations as a function of the composition of the RP using Eq. (29) for two examples, where $c_{1}=c_{2}$ and $c_{1}>c_{2}$. The values of parameters used in two examples are summarized in Table 3 and all values are within the ranges of actual aluminum recycling operational conditions with the reduced dimensionality and normalized production volume.

Figure 3 shows the unit material cost of individual products and the TMC as a function of the composition of the RP $\left(\varepsilon_{p}\right)$ for the two examples. The feasible composition for the RP (the x-axis of graphs in Figure 3) ranges from the composition of Scrap 1 to Scrap 2 (0.2\% 1.4\%). Figure 3(a) shows how the minimum cost of producing each product changes with the composition of the RP. In the first 
example, the unit material cost of the RP is constant regardless of its composition. For each product, the unit cost decreases as the composition of the RP approaches the minimum specification because less of the alloying element is required. The unit cost of each product is lowest when the composition of the RP is within the range of product specifications. Once the composition of the RP exceeds the maximum specification, the unit cost of the individual products increases.

Table 3. The values of parameters used in two examples

\begin{tabular}{rcc}
\hline & Example1 & Example 2 \\
\hline Scrap 1 price $\left(\boldsymbol{c}_{\boldsymbol{1}}\right)$ & $\$ 1750 / \mathrm{t}$ & $\$ 1900 / \mathrm{t}$ \\
Scrap 2 price $\left(\boldsymbol{c}_{\mathbf{2}}\right)$ & $\$ 1750 / \mathrm{t}$ & $\$ 1600 / \mathrm{t}$ \\
Primary metal price $\left(\boldsymbol{c}_{\boldsymbol{3}}\right)$ & $\$ 2137 / \mathrm{t}$ \\
Alloying element price $\left(\boldsymbol{c}_{\boldsymbol{4}}\right)$ & $\$ 2689 / \mathrm{t}$ \\
Scrap 1 composition $\left(\boldsymbol{e}_{\mathbf{1}}\right)$ & $0.2 \%$ \\
Scrap 2 composition $\left(\boldsymbol{e}_{2}\right)$ & $1.4 \%$ \\
Product A specification $\left(\left[\boldsymbol{e}_{\boldsymbol{A}}^{\boldsymbol{L}}, \boldsymbol{e}_{A}^{\boldsymbol{U}}\right]\right)$ & {$[0.4 \%, 0.6 \%]$} \\
Product B specification $\left(\left[\boldsymbol{e}_{\boldsymbol{B}}^{\boldsymbol{L}}, \boldsymbol{e}_{\boldsymbol{B}}^{\boldsymbol{U}}\right]\right)$ & {$[0.9 \%, 1.1 \%]$} \\
Product A Demand $\left(\boldsymbol{D}_{\boldsymbol{A}}\right)$ & $1 \mathrm{t}$ \\
Product B Demand $\left(\boldsymbol{D}_{\boldsymbol{B}}\right)$ & $1 \mathrm{t}$
\end{tabular}

The asymmetric cost behavior originates from the amount of primary aluminum and the alloying element needed to adjust the composition of the RP. When the RP is below the minimum specification, the amount of the alloying element used in the final products $\left(f_{4 A}\right.$ or $\left.f_{4 B}\right)$ is $\frac{e_{t}^{L}-\varepsilon_{p}}{e_{4}-\varepsilon_{p}}$, for $t=A$ or $B$. Meanwhile, when the RP is above the maximum specification, the amount of primary metal used in the final products $\left(f_{3 A}\right.$ or $f_{3 B}$ ) is $\frac{\varepsilon_{p}-e_{t}^{U}}{\varepsilon_{p}-e_{3}}$ for $t=A$ or $B$. Scrap materials typically consist more of primary metal than of alloying elements. Thus, the compositional distance between primary metal and scrap materials (or the RP) is much narrower than that between scrap materials and alloying elements, resulting in a significantly smaller numerator compared to the denominator (i.e., $e_{t}^{L}-\varepsilon_{p} \ll e_{4}-\varepsilon_{p}$ ) for $f_{4 t}$ when $\varepsilon_{p}<e_{t}^{L}$. This also means that only a small amount of the alloying element is needed to meet the specifications of the final products. On the other hand, the numerator and the denominator have relatively similar values for $f_{3 t}$, when $\varepsilon_{p}>e_{t}^{U}$ (i.e., $\varepsilon_{p}-e_{t}^{U} \approx \varepsilon_{p}$ ). Thus, the value of $f_{3 t}$ is significantly larger than zero. As a result, the amount of primary aluminum required to dilute the RP when $\varepsilon_{p}>e_{t}^{U}$ is much larger than the amount of the alloying element required to concentrate the RP when $\varepsilon_{p}<e_{t}^{L}$ (see Figure $\mathrm{S} 1$ in SI for the use of individual raw materials and the RP in final products as a function of the composition of the RP). 
(a)

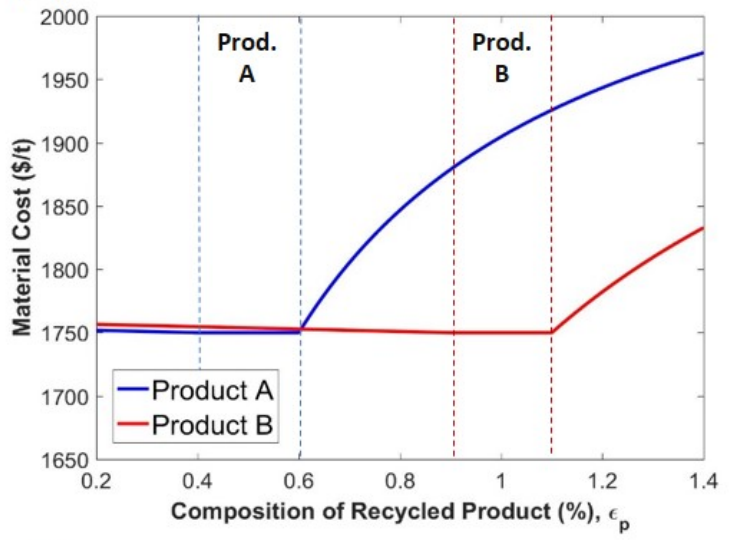

(c)

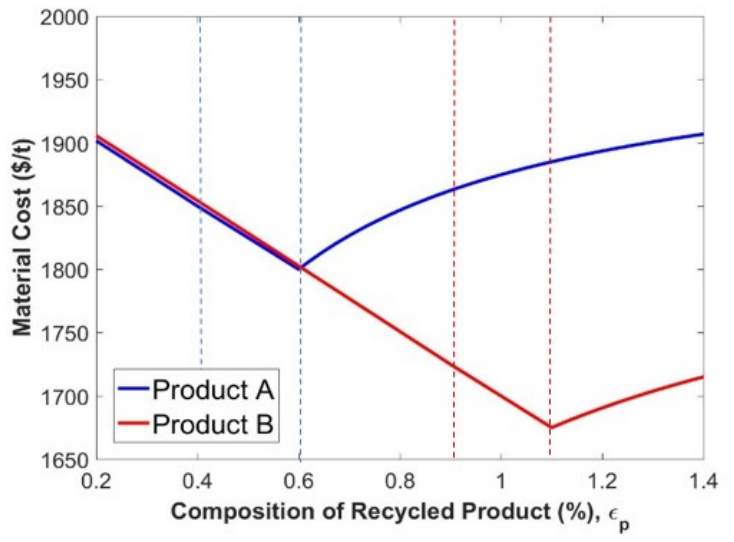

(b)

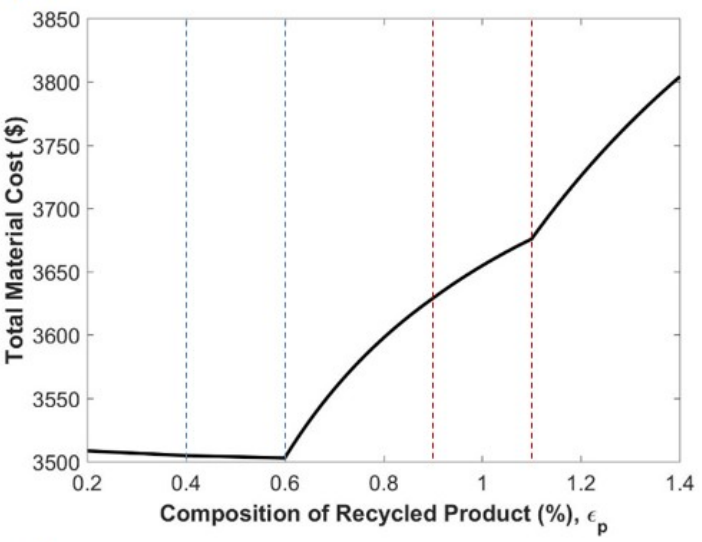

(d)

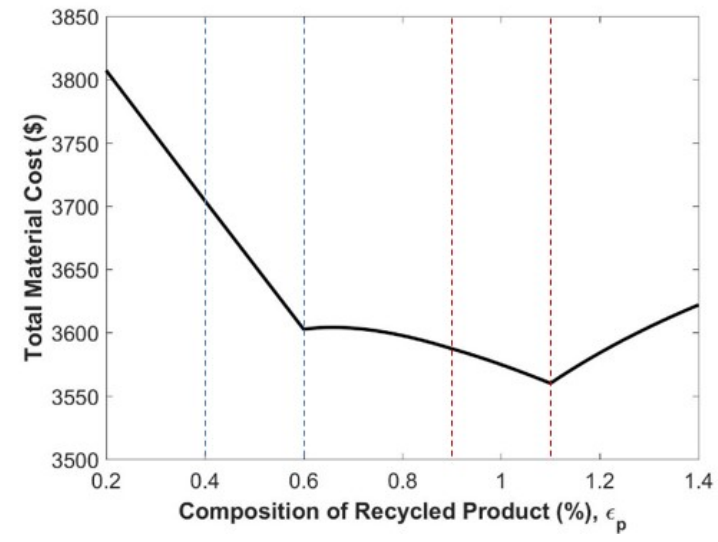

Figure 3. Plots of (a) per unit material cost of Product $A$ and $B$ as a function of the composition of the RP when $c_{1}=c_{2}$, (b) the total material cost as a function of the composition of the RP when $c_{1}=c_{2}$, (c) per unit material cost of Product $A$ and $B$ as a function of the composition of the RP when $c_{1}>c_{2}$, and (d) the total material cost as a function of the composition of the RP when $c_{1}>$ $c_{2}$.

Because of the required volume, the cost of adding the alloying element is significantly cheaper than the cost of diluting with primary aluminum, despite the higher price of the alloying element. Hence, the optimal composition of the RP is the maximum specification of Product $\mathrm{A}$, which is the minimum of maximum specifications among two products, as shown in Figure 3(b). In this example, the cost of producing the RP is constant across all possible compositions. Nonetheless, the TMC varies from $\$ 3500$ to more than $\$ 3800$, which is almost a $10 \%$ difference, depending on the composition of the RP. This difference in material cost is driven by the use of primary metal.

In DP, if an aluminum producer uses a predetermined recipe, the RP compositions could fall anywhere in the range among the available scraps. If an aluminum producer uses a predetermined design for the RP, a common strategy is to aim for the RP composition at the lowest alloying element 
concentration across many different final products to avoid being outside of the maximum specification. These blends are often called master alloys since material producers only need to add small amounts of alloying elements to meet product specifications without significant increases in the cost. This practice is aligned to the asymmetric cost behaviors explained in this example. For the same reason, scrap with lower alloying element concentration often has a higher price due to its applicability, In addition, if an aluminum producer cannot achieve the purest alloy specification for the RPs due to limited availability of scrap with lower alloying element concentrations, it either chooses a predetermined recipe or opts out of a two-stage recycling operation by selling all RPs as sows. Our following example shows that the predetermined design of a master alloy is not always the best design for the RPs, especially when the scrap with lower alloying element concentrations has a higher price.

Figures 3(c) and 3(d) show the unit cost of products and the TMC, respectively, as a function of the composition of the RP for $c_{1}>c_{2}$. The material cost of an individual product decreases until the composition of the RP reaches the maximum of the product specification for two reasons. First, increasing the composition of the RP reduces the amount of the alloying element added to a final product up to the minimum of each product specification, which is also observed in the previous case of $c_{1}=c_{2}$. Second, the RP can be produced at lower cost using the cheaper raw material (Scrap 2), consequently reducing the product cost of final products. This latter benefit is significant because the amount of the RP used in final products increases until the composition of the RP reaches the maximum of specification of the individual products.

For $c_{1}>c_{2}$, the unit cost of the RP is $\$ 1800$ when $\varepsilon_{p}=0.6 \%$, but $\$ 1675$ when $\varepsilon_{p}=1.1 \%$. Switching the composition of the RP from $0.6 \%$ to $1.1 \%$ increases the unit cost of Product A by $\$ 85$ due to the increased use of primary aluminum. However, the decreased unit cost of Product B due to the reduced cost of the RP outweighs the increased cost in Product A. As a result, the TMC is lowest when the composition of the RP is the maximum specification of Product B, as shown in Figure 3(d).

The results from the $c_{1}>c_{2}$ analysis reveal the limitation of applying a master alloy strategy. If the estimated composition of the RP is the maximum specification of Product A (0.6\%) in $c_{1}>c_{2}$, the TMC is $\$ 3603$. Switching the composition of the RP to the maximum specification of Product B (1.1\%) can further reduce the TMC to $\$ 3560$, resulting in an additional 1.2\% saving. This benefit found in the small hypothetical case motivates further investigation into the benefits of IP in two-stage blending.

Industrial-sized problems are much more complex than this hypothetical case. Operations in recycling typically consist of multiple products, various raw materials, many different alloying elements, and other constraints such as the availability of raw materials and the capacity of the furnace. Due to the 
interdependence of the design of the RPs and the material cost, we demonstrate, in the next section, how the IP model improves the current practice of a real-world recycling operation.

\section{Case example to illustrate the benefit of integrated planning, compared to disjointed} planning in the context of aluminum recycling

Here we demonstrate the benefits of IP in the context of a real-world case of aluminum recycling. The recycling facility has one rotary furnace and two remelting furnaces. Each furnace produces four batches per day, resulting in four batches for RPs $(l)$ and eight batches for final products per day $(t)$. Eighteen final products are produced in this facility. The daily batches can be any of these eighteen products. The reprocessing stage uses eleven different types of scrap materials, along with the aluminum dross collected from the earlier batches of final alloy production $(i)$, to produce RPs. Depending on the production schedule, a maximum of eight different types of dross can be available each day. RPs produced in a rotary furnace can be delivered to either remelting furnace $\left(q_{l, t}\right.$ or $\left.f_{l, t}\right)$. The portion of RPs not used in final alloy production must be cast as sows $\left(r_{l}\right.$ or $\left.R_{l}\right)$. In addition, primary aluminum and six alloying elements $(j)$ are available in the remelting stage. Six compositional elements ( $\mathrm{Si}, \mathrm{Fe}, \mathrm{Mn}, \mathrm{Mg}, \mathrm{Fe}$, and $\mathrm{Cu}$ ) are tracked in this example. (The actual operations may track many more elements. The model presented here can be extended without modification in conjunction with considerations of thermodynamic effects of remelting (Reuter, van Schaik, Ignatenko, \& de Haan, 2006).) The IP and DP models described in the previous section are implemented and solved for a daily plan in LINGO 16.0 (LINGO, 2016). We assume that each stage can be scheduled each day so that the RPs produced in the reprocessing stage can be immediately used as inputs in the remelting stage. An example of how the batches are scheduled is illustrated in Figure S2 in SI.

As we discussed in the previous section, aluminum producers often use the specification of the final product with the lowest alloying elements (the purest alloy product) as the predetermined recipe for the RPs while still using a one-stage blending model. Such an approach is possible when scraps with low alloying element concentration are abundant. Otherwise, only a limited volume of RPs can be produced. Thus, we use the predetermined recipe approach in this study. Although there are many options for the predetermined recipe for the reprocessing stage, we use a recipe that blends all available dross and scrap in equal proportions for all four batches a day. However, the resulting compositions of the RPs can differ depending on the availability of raw materials at the time of each batch. Consequently, the use of RPs produced in DP varies depending on their compositional compatibility with the specification of final products. We ran the proportional formulation of the IP model and the DP model to determine a daily batch plan. This is consistent with the current practice of this recycling facility since it updates its inventory of raw materials on a daily basis. We tested the two models over several different days. We 
present here the results from a representative day with average performance. Detailed information for the compositions and prices of raw materials as well as the specifications of final products in the case study facility is provided in SI.

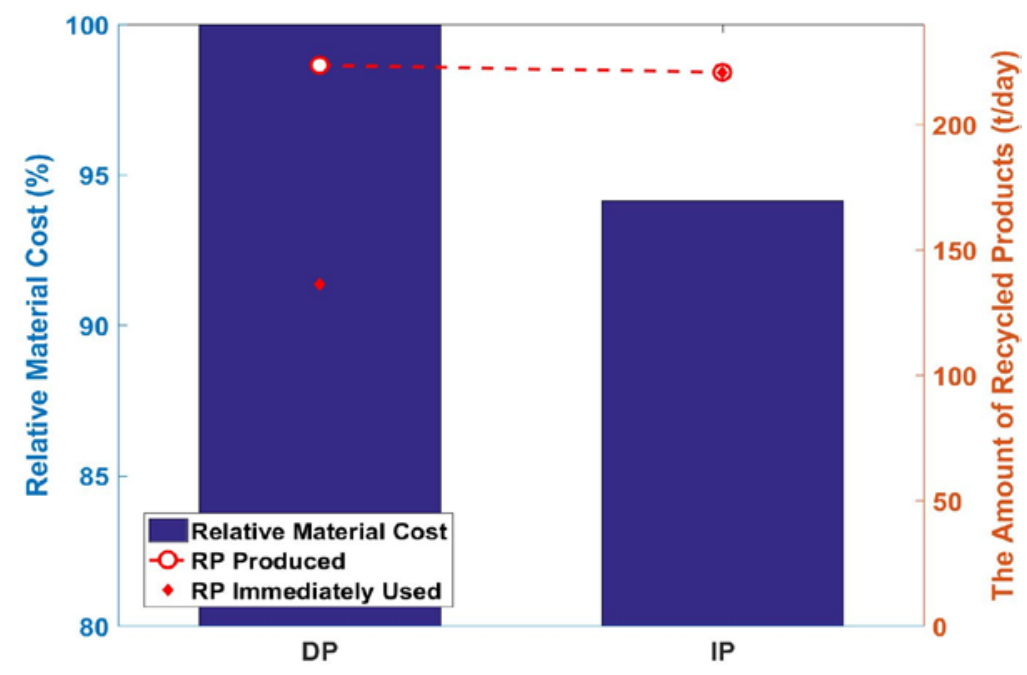

Figure 4. Batch plan performance for a single day between DP and IP for relative total material cost normalized by cost in DP (bar graph, left y-axis), the amount of RPs produced (open circle and dash line, right $y$-axis) and the amount of RPs that are immediately used in final product productions (diamond, right y-axis).

Figure 4 shows the resulting performance of DP and IP in a daily operation. The red open circles and diamonds in Figure 4 represent the total amount of RPs produced and the amount of RPs used immediately in the remelting stage, respectively. The difference between the open circle and diamond is the amount of RPs cast as sows (lower value product). The amount of RPs produced in DP and IP are similar: 224t per day and 221t per day, respectively. As shown in Figure 4, only 136t/day of the RPs are immediately used in final products in DP, resulting in casting 87t/day as sows, whereas in IP all RPs produced are incorporated in finished alloy products without casting them as sows. The compositional mismatch between final products and RPs produced using predetermined recipes accounts for the limited use of RPs in DP. The final products in IP have more than $60 \%$ recycled content, compared to $39 \%$ for DP.

In Figure 4, we also show the material cost difference between the DP and IP. The IP material cost is $94 \%$ of the material cost in DP. This material cost includes only the cost of raw materials used in final alloy products. The DP material cost does not include the cost of the raw materials that were used to produce RPs that are not used. Hence, this cost savings results from replacing primary aluminum and alloying elements by RPs, which are made of less expensive raw materials. The results from the case 
study are consistent with the conclusions drawn from the hypothetical case. The IP model outperforms the DP model because it precisely determines the best design for the RPs that minimize the TMC based on the batch plans in the remelting stage.

The results in Figure 4 do not account for the possibility that the DP might use sows existing in the inventory, which would reduce its reliance on primary aluminum and alloying elements. As such, the material cost difference in Figure 4 provides an upper bound of the benefits of the IP. However, there is an energy benefit in IP in addition to material cost saving. Since all RPs are immediately incorporated in final alloy production without being cast as sows, material producers avoid energy costs associated with melting sows for later batches. The theoretical energy required to remelt $87 \mathrm{t}$ of the RPs that are not immediately used in final alloy production is about 122,148MJ (Green, 2007). Depending on the efficiency of the melting furnace, roughly two to five times this energy is required in DP. The cost of energy is one of the major cost elements determining profitability for a remelter, other than raw material purchasing (Goddard, 2014). For example, even if the material cost of DP can be reduced by using sows previously produced, we estimate that the cost to remelt $87 \mathrm{t}$ of sows is $2 \%$ of the total material cost in IP based on the average cost of the industry. Therefore, the energy savings that can be achieved by using the proposed IP model is a strong advantage for the aluminum producer.

The potential direct energy savings and $\mathrm{CO}_{2}$ emission reduction using IP in this case study are presented in Table 4. The values only include savings in the remelting stage due to immediate use of RPs as liquid metal. In addition, there would be potential upstream energy savings by replacing primary aluminum consumption with undervalued raw materials. For example, the total energy requirement for primary metal production is $95 \mathrm{GJ} / \mathrm{t}$ of $\mathrm{Al}$ compared to $4.3 \mathrm{GJ} / \mathrm{t}$ required for secondary metal (Moya et al., 2015). However, upstream emissions can vary depending on the regional scrap availability and source of primary metal.

Table 4. Potential energy saving and $\mathrm{CO}_{2}$ emission reduction per year in the remelting stage by using integrated planning in the case study. (The calculation assumes 250 days operation per year and the similar performance difference between DP and IP throughout year as shown in Figure 4. The spread of the energy value is due to the energy efficiency of furnace (Das, 2007; Green, 2007). The minimum and maximum values among OECD European countries are used for $\mathrm{CO}_{2}$ emission factors per kWh electricity generation (IEA, 2017). )

\begin{tabular}{|c|c|c|}
\hline & \multicolumn{2}{|c|}{ Potential Environmental Benefit using IP } \\
\hline & Energy saving (MWh/year) & $\mathrm{CO}_{2}$ emission reduction (t of $\mathrm{CO}_{2}$ /year) \\
\hline Minimum & 18,850 & 170 \\
\hline Maximum & 42,413 & 43,515 \\
\hline
\end{tabular}


We also investigate under what conditions IP is most beneficial, compared to DP. We perform a sensitivity analysis on selected operational parameters: the capacity of the reprocessing furnace as well as the price and availability of low-quality scrap. These parameters are associated with the first-stage blending process. The parameters associated with the second blending stage, such as product specifications and demand, are not included in this analysis. As mentioned earlier, the final alloy products in our case study are mostly made of primary feedstocks and sold as high-end products in the market. Since this study explores the potential opportunity of using recovered low-quality feedstocks in the existing production of high-end alloy products through IP, the goal of this sensitivity analysis is to inform material producers under what conditions IP can help them to maximize the benefits by planning with the existing reprocessing stage.

Figure 5(a) shows the results of the sensitivity analysis for the capacity of the reprocessing furnace. We define the capacity multiplier as the relative capacity of the reprocessing furnace to the sum of each batch size in two downstream remelting furnaces. The results in Figure 4 are for the case when this multiplier is equal to one. Figure 5(a) presents how the capacity of a reprocessing furnace significantly affects the benefit of using the IP model over the DP one. The bar graph (left y-axis) represents the material cost savings of IP over DP depending on the capacity of the reprocessing furnace. The capacity of the reprocessing furnace sets the limit for maximum production of the RPs. The blue solid line and red dashed line with right y-axis in Figure 5(a) show the amount of RPs produced during four batches a day for both IP and DP, respectively. The blue dots and red diamonds represent the amount of RPs that are immediately incorporated in the remelting stage. Across all capacity levels, all RPs produced in IP are immediately used in the remelting stage. At a larger capacity of the reprocessing furnace, only some RPs are immediately incorporated in DP. However, at a smaller capacity, the majority of RPs produced are instantly used in the remelting stage even for DP. Since only a limited amount of RPs can be produced at a smaller capacity, the proportion of RPs in the final products is also smaller. Primary metal and alloying elements are used in the remelting furnace to meet production that cannot be sourced from RPs. Even if the compositions of RPs do not fit well with the final alloy products, they can be easily diluted with primary aluminum. Thus, the composition of RPs becomes less critical when there is less capacity in the reprocessing furnace. For this reason, the material cost difference between IP and DP becomes significantly less when the capacity multiplier is 0.25 as shown in Figure 5(a).

Moreover, Figure 5(a) implies an upper limit of the benefit from having a larger reprocessing furnace. Clearly, there is no need for a reprocessing furnace whose capacity is bigger than the sum of each batch sizes of downstream remelting furnaces. As shown in Figure 5(a), the relative cost saving from IP reaches saturation when the capacity multiplier is close to one. In fact, the reprocessing furnace is not 
fully loaded in some batches when the multiplier is one. Therefore, integrating planning with the reprocessing stage that has a high capacity may cause underutilization of the reprocessing furnace.

Figure 5(b) shows the results of the sensitivity analysis to the price of scrap materials. The scrap materials available in the case study are categorized into six groups based on their grade and source. Among them, three groups are considered particularly low-quality scrap. They exhibit relatively lower yield than the other three groups, have high concentrations of alloying elements, and are therefore cheaper. We introduce the price multiplier on scrap to differentiate these three groups from the rest of the scrap. When this multiplier is one, the prices of low-quality scrap materials are at their maximum. The results in Figure 5(b) show how the benefit of using the IP model changes with changes in the price multiplier. Although IP performs better than DP for all cases in terms of both the material cost and the amount of RPs immediately used in the remelting furnace, the benefit of using IP is the largest when low-quality scrap is much cheaper than high-quality scrap. Since DP uses a predetermined recipe, the compositions of produced RPs are constant regardless of price changes of low-quality scrap. However, IP dynamically modifies the compositions and production volumes of RPs depending on the prices of materials. The IP model allows material producers to take advantage of cheaper scrap materials by using them more aggressively in the production of RPs.

Figure 5(c) shows the result of the sensitivity analysis on the availability of low-quality scrap in the three groups explained above. Since the price of low-quality scrap is lower (the price multiplier of low-quality scrap is set to 0.9 in this analysis), IP tries to maximize the use of low-quality scrap depending on its availability. Hence, when low-quality scrap becomes more available, IP increases the use of this material and produces more RPs as shown in Figure 5(c). However, DP does not utilize the potential opportunity to reduce the material cost in the downstream remelting stage by using cheaper raw materials. As a result, the cost saving of IP increases with the increased availability of low-quality scrap. The impact of the availability parameter is clearly conditional since the low-quality scrap must be inexpensive to increase its use upon increased availability. 
(a)

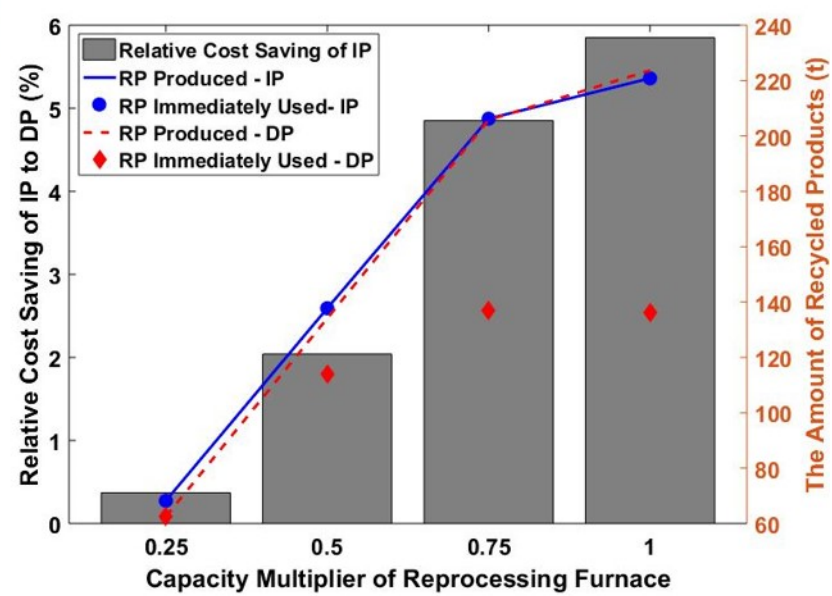

(b)

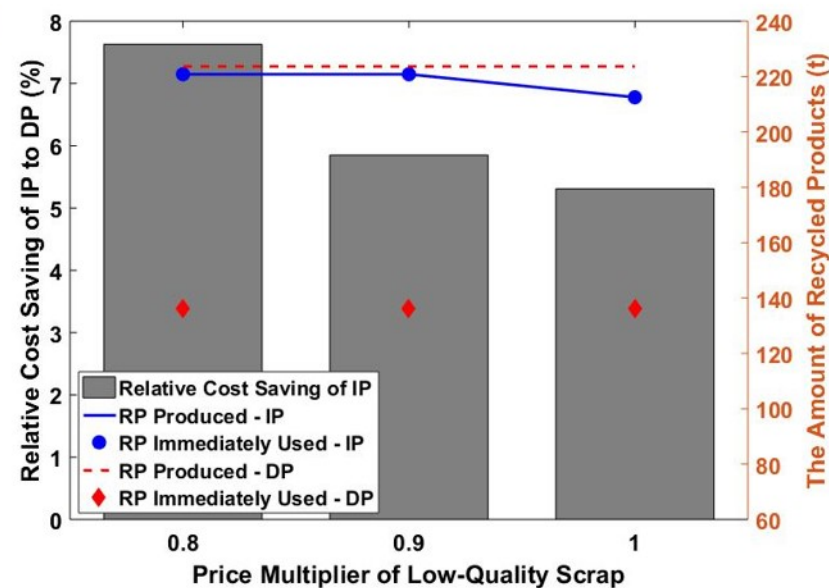

(c)

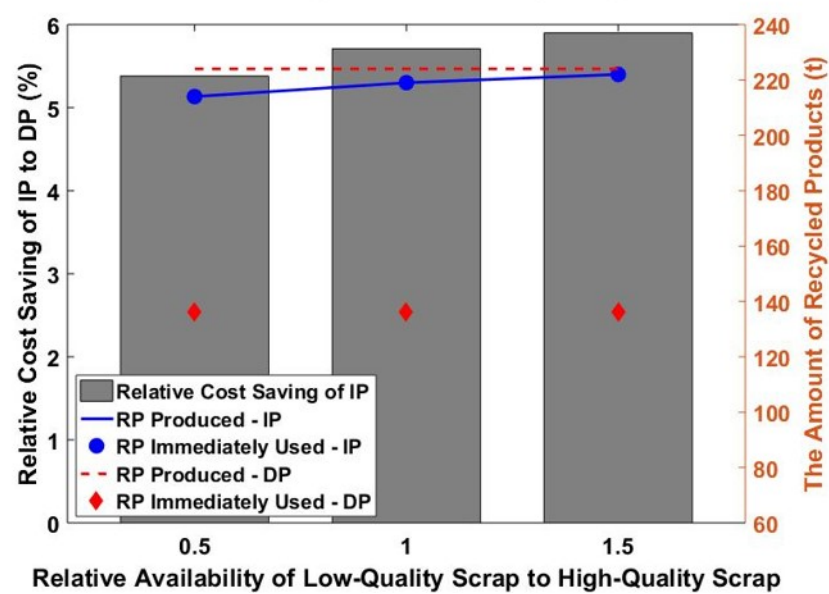

Figure 5. The results from the sensitivity analysis on (a) the capacity multiplier (b) the price multiplier on low-quality scrap and (c) the relative availability of low-quality scrap to high-quality scrap. Bar graphs correspond with the left y-axis showing the relative material cost saving of IP to DP. The blue solid and red dashed lines correspond with the right y-axis showing the amount of RPs produced in IP and DP, respectively. The blue circles and red diamonds correspond with the right y-axis showing the amount of RPs immediately used in IP and DP, respectively. 
All of the results from the sensitivity analysis show that IP outperforms DP in terms of material cost. Furthermore, the results suggest that IP is particularly beneficial when the capacity of the reprocessing furnace is larger and when low-quality scrap is cheaper and more available. The capacity of the reprocessing furnace is the most significant parameter because it determines an upper bound on how much primary metal can be replaced by the RPs. Depending on the capacity, the cost saving of using IP varies from $0.37 \%$ to $5.9 \%$. Meanwhile, changes in relative cost saving due to the price and the availability of low-quality scrap are only about $2 \%$ and less than $1 \%$, respectively. Savings in material cost up to $6 \%$ are significant, considering the fact that about $70 \%$ of revenue is absorbed by purchasing raw materials, and the profit margin is only 5\% in the aluminum industry (Goddard, 2014).

\section{Conclusion}

In this paper, we have shown how the design of intermediate blends influences the overall performance of a two-stage recycling operation. The current practice of disjointed planning for two-stage recycling operations stems largely from reliance on historical practice and the fact that sow pricing focuses only on metal content. This disjointed approach results in underutilization of secondary raw materials in high-value products despite their potential benefits. The proposed IP model can determine the optimal designs of intermediate blends and the optimal blending decisions in both stages simultaneously. This model has been applied to a two-stage aluminum recycling facility located in Europe. The results of the case study show that IP can significantly improve the performance of the two-stage recycling operation in terms of the total material costs and energy saved by delivering RPs in liquid form. In addition to the case introduced here, this study has also informed the model development for two other recycling facilities having similar technology capability with modifications to fit the contexts of the plants.

A two-stage blending operation is not limited to aluminum recycling. The IP model can apply to other metal recycling operations without major modification where quality attributes are defined as the quantity of alloying elements. For materials other than metals, one would modify the expressions of quality attributes accordingly (such as fiber length in paper or molecular weight in polymers (Olivetti, Gaustad, Field, \& Kirchain, 2011)). Industries that require some manifestation of a two-stage system for processing secondary material (such as steel, pulp and paper, and aluminum) are major contributors to industrial energy consumption and GHG emissions. The current share of global industrial energy use of steel, pulp and paper and aluminum industries are 20\%, 20\% and 13\%, respectively. The share of industrial GHG emissions for these three industries are 14\%, 20\%, and 12\%, respectively (IEA, 2009). Secondary steel production uses about 54-73\% less energy than primary steel production (IEA, 2009; U.S. EPA, 2012). Recycled pulp production requires $10-30 \%$ of energy requirement for virgin pulp production (Kramer, Masanet, Xu, \& Worrell, 2011), although the source of this energy changes significantly 
between virgin and recycled pulp. Therefore, improved decision-making for sustainable resource uses through IP can reduce environmental impacts in addition to increasing the profitability of material producers.

There remain research opportunities to extend and enhance the IP formulation. For instance, some recycling facilities recently have adopted reprocessing technologies that carry over intermediate blends; the resulting recycling process is then a multi-stage operation. Our formulation, which can be categorized as the standard pooling problem, allows flows only from sources to pools, from sources to terminals, and from pools to terminals. A multi-stage recycling operation allows flows between pools and would require a modification to the IP model.

To conclude, material producers need to extend the scope of their planning, which requires a certain degree of coordination between two different operational units. Significant improvement can be achieved by planning the two stages jointly using the IP model. The potential savings presented in this paper do not require any capital investment since both stages currently exist. Although establishing an integrated information system often necessitates additional investment, in general, this cost is relatively small, compared to capital costs. Therefore, material producers should consider the potential savings from operational tools that allow full realization of the benefits of improved reprocessing technologies.

\section{Acknowledgements}

The authors would like to acknowledge partial support from both the National Science Foundation Award \#1605050, CBET program and from National Funds through FCT - Fundação para Ciência e a Tecnologia in the scope of project MITP-TB/PFM/0005/2013 as well as support from Norsk Hydro aluminum company. The authors also thank the anonymous referees for detailed inputs that improved this study.

\section{References}

Adhya, N., Tawarmalani, M., \& Sahinidis, N. V. (1999). A Lagrangian Approach to the Pooling Problem. Industrial \& Engineering Chemistry Research, 38, 1956-1972. http://doi.org/10.1021/ie980666q

Ashayeri, J., van Eijs, A. G. M., \& Nederstigt, P. (1994). Blending modelling in a process manufacturing: A case study. European Journal of Operational Research, 72(3), 460-468. http://doi.org/10.1016/0377-2217(94)90416-2

Audet, C., Brimberg, J., Hansen, P., Digabel, S. Le, \& Mladenović, N. (2004). Pooling Problem: Alternate Formulations and Solution Methods. Management Science, 50(6), 761-776. http://doi.org/10.1287/mnsc.1030.0207

Ayres, R., Ferrer, G., \& Van Leynseele, T. (1997). Eco-efficiency, asset recovery and remanufacturing. European Management Journal, 15(5), 557-574. http://doi.org/10.1016/S0263-2373(97)00035-2

Ben-Tal, A., Eiger, G., \& Gershovitz, V. (1994). Global minimization by reducing the duality gap. 
Mathematical Programming, 63(1), 193-212. http://doi.org/10.1007/BF01582066

Bloemhof-Ruwaard, J. M., van Beek, P., Hordijk, L., \& Van Wassenhove, L. N. (1995). Interactions between operational research and environmental management. European Journal of Operational Research, 85(2), 229-243. http://doi.org/10.1016/0377-2217(94)00294-M

Chang, J. C. (2015). Designing two-stage recycling operations for increased usage of undervalued raw materials. Massachusetts Institute of Technology. Retrieved from http://hdl.handle.net/1721.1/101795

Das, S. K. (2007). Improving Energy Efficiency in Aluminum Melting DE-FC07-01ID14023, Final Technical Report. Retrieved from www.phinix.net/services/Energy_Management/Improving_Energy_Efficiency.pdf

DeWitt, C. W., Lasdon, L. S., Waren, A. D., Brenner, D. A., \& Melhem, S. A. (1989). OMEGA: An Improved Gasoline Blending System for Texaco. Interfaces, 19(1), 85-101. http://doi.org/10.1287/inte.19.1.85

European Council. (2011). Council Directive 2011/97/EU. Official Journal of the European Communities, (L328).

Fabian, T. (1958). A Linear Programming Model of Integrated Iron and Steel Production. Management Science, 4(4), 415-449. http://doi.org/10.1287/mnsc.4.4.415

Fröhling, M., Schwaderer, F., Bartusch, H., \& Rentz, O. (2010). Integrated planning of transportation and recycling for multiple plants based on process simulation. European Journal of Operational Research, 207(2), 958-970. http://doi.org/10.1016/j.ejor.2010.04.031

Galbreth, M. R., \& Blackburn, J. D. (2006). Optimal Acquisition and Sorting Policies for Remanufacturing. Production and Operations Management, 15(3), 384-392. http://doi.org/10.1111/j.1937-5956.2006.tb00252.x

Gaustad, G., Li, P., \& Kirchain, R. (2007). Modeling methods for managing raw material compositional uncertainty in alloy production. Resources, Conservation and Recycling, 52(2), 180-207. http://doi.org/10.1016/j.resconrec.2007.03.005

Goddard, L. (2014). Light is right: Globalization and the growing popularity of fuel-efficient cars will spur demand. IBISWorld Industry Report, 33131(Aluminum Manufacturing in the US).

Govindan, K., Soleimani, H., \& Kannan, D. (2015). Reverse logistics and closed-loop supply chain: A comprehensive review to explore the future. European Journal of Operational Research, 240(3), 603-626. http://doi.org/10.1016/J.EJOR.2014.07.012

Green, J. A. S. (2007). Aluminum Recycling and Processing for Energy Conservation and Sustainability. ASM International.

Guide, V. D. R., Jayaraman, V., Srivastava, R., \& Benton, W. C. (2000). Supply-Chain Management for Recoverable Manufacturing Systems. Interfaces, 30(3), 125-142. http://doi.org/10.1287/inte.30.3.125.11656

Haverly, C. A. (1978). Studies of the behavior of recursion for the pooling problem. ACM SIGMAP Bulletin, (25), 19-28. http://doi.org/10.1145/1111237.1111238 
IAI. (2017). Global Mass Flow Model - 2016. International Aluminum Institute. Retrieved from http://www.world-aluminium.org/publications/\#822

IEA. (2009). Energy Technology Transitions for Industry: Strategies for the Next Industrial Revolution. PAris: OECD Publishing. http://doi.org/http://dx.doi.org/10.1787/9789264068612-en

IEA. (2017). CO2 Emissions from Fuel Combustion 2017, OECD Publishing, Paris. Retrieved from http://dx.doi.org/10.1787/co2_fuel-2017-en

Jayaraman, V. (2006). Production planning for closed-loop supply chains with product recovery and reuse: an analytical approach. International Journal of Production Research, 44(5), 981-998. http://doi.org/10.1080/00207540500250507

Johnson, M. R., \& Wang, M. H. (1995). Planning product disassembly for material recovery opportunities. International Journal of Production Research, 33(11), 3119-3142. http://doi.org/10.1080/00207549508904864

Kirchain, R., \& Cosquer, A. (2007). Strategies for maintaining light metal reuse: Insights from modeling of firm-wide raw materials availability and demand. Resources, Conservation and Recycling, 51(2), 367-396. http://doi.org/10.1016/j.resconrec.2006.10.005

Kramer, K. J., Masanet, E., Xu, T., \& Worrell, E. (2011). Energy efficiency improvement and cost saving opportunities for the pulp and paper industry. In Improving Energy Efficiency and Greenhouse Gas Reduction in the Pulp and Paper Industry (pp. 51-210). Berkeley, CA: Nova Science Publishers, Inc.

Li, X., Armagan, E., Tomasgard, A., \& Barton, P. I. (2011). Stochastic pooling problem for natural gas production network design and operation under uncertainty. AIChE Journal, 57(8), 2120-2135. http://doi.org/10.1002/aic.12419

LINGO. (2016). Optimization Modeling Software for Linear, Nonlinear, and Integer Programming. LINDO SYSTEMS INC. Retrieved from https://www.lindo.com

Meyer, C. A., \& Floudas, C. A. (2006). Global optimization of a combinatorially complex generalized pooling problem. AIChE Journal, 52(3), 1027-1037. http://doi.org/10.1002/aic.10717

Moya, J. A., Boulamati, A., Slingerland, S., van der Veen, R., Gancheva, M., Rademaekers, K. M., ... Visschedijk, A. J. H. (2015). Energy Efficiency and GHG Emissions: Perspective Scenarios for the Aluminum Industry. Retrieved from http://publications.jrc.ec.europa.eu/repository/handle/JRC96680

Olivetti, E. A., Gaustad, G. G., Field, F. R., \& Kirchain, R. E. (2011). Increasing Secondary and Renewable Material Use: A Chance Constrained Modeling Approach To Manage Feedstock Quality Variation. Environmental Science \& Technology, 45(9), 4118-4126. http://doi.org/10.1021/es103486s

Peterson, R. D., \& Blagg, G. G. (2013). Transportation of Molten Aluminum. In Recycling of Metals and Engineered Materials (pp. 857-866). John Wiley \& Sons, Inc. http://doi.org/10.1002/9781118788073.ch75

Quesada, I., \& Grossmann, I. E. (1995). Global optimization of bilinear process networks with multicomponent flows. Computers \& Chemical Engineering, 19(12), 1219-1242. http://doi.org/10.1016/0098-1354(94)00123-5 
Raz, G., \& Souza, G. C. (2018). Recycling as a Strategic Supply Source. Production and Operations Management, 27(5), 902-916. http://doi.org/10.1111/poms.12851

Reuter, M. A., van Schaik, A., Ignatenko, O., \& de Haan, G. J. (2006). Fundamental limits for the recycling of end-of-life vehicles. Minerals Engineering, 19(5), 433-449. http://doi.org/10.1016/j.mineng.2005.08.014

Rong, A., \& Lahdelma, R. (2008). Fuzzy chance constrained linear programming model for optimizing the scrap charge in steel production. European Journal of Operational Research, 186(3), 953-964. http://doi.org/10.1016/j.ejor.2007.02.017

Salema, M. I. G., Barbosa-Povoa, A. P., \& Novais, A. Q. (2010). Simultaneous design and planning of supply chains with reverse flows: A generic modelling framework. European Journal of Operational Research, 203(2), 336-349. http://doi.org/10.1016/j.ejor.2009.08.002

Schlesinger, M. E. (2013). Aluminum Recycling, Second Edition. CRC Press. Retrieved from https://books.google.com/books?id=xF_OBQAAQBAJ

Spengler, T., Püchert, H., Penkuhn, T., \& Rentz, O. (1997). Environmental integrated production and recycling management. European Journal of Operational Research, 97(2), 308-326. http://doi.org/10.1016/S0377-2217(96)00200-7

Steuer, R. E. (1984). Sausage Blending Using Multiple Objective Linear Programming. Management Science, 30(11), 1376-1384. http://doi.org/10.1287/mnsc.30.11.1376

Symonds, G. H. (1956). Linear Programming Solves Gasoline Refining and Blending Problems. Industrial \& Engineering Chemistry, 48(3), 394-401. http://doi.org/10.1021/ie51398a018

Thierry, M., Salomon, M., Van Nunen, J., \& Van Wassenhove, L. (1995). Strategie Issues in Product Recovery Management. California Management Review, 37(2), 114-135. Retrieved from http://cmr.ucpress.edu/content/37/2/114.abstract

U.S. EPA. (2012). Available and emerging technologies for reducing greenouse gas emissions from the iron and steel industry. Research Triangle Park, North Carolina.

van Schaik, A., Reuter, M. A., Boin, U. M. J., \& Dalmijn, W. L. (2002). Dynamic modelling and optimisation of the resource cycle of passenger vehicles. Minerals Engineering, 15(11), 1001-1016. http://doi.org/10.1016/S0892-6875(02)00080-8

Vercammen, S., Chalabyan, A., Ramsbottom, O., Ma, J., \& Tsai, C. (2017, March). Tsunami, spring tide, or high tide? The growing importance of steel scrap in China. Mckinsey\&Company - Metals and Mining Practice. 